\title{
Institutional quality causes social trust: Experimental evidence on trusting under the shadow of doubt
}

\section{Andrea Martinangeli}

Max Planck Institute for Tax Law and Public Finance https://orcid.org/0000-0001-9823-6860

Marina Povitkina (D marina.povitkina@gu.se)

University of Oslo https://orcid.org/0000-0003-2548-5027

Sverker Jagers

University of Gothenburg

Bo Rothstein

University of Gothenburg

\section{Article}

Keywords: social science, social trust, institutional quality

Posted Date: January 29th, 2021

DOI: https://doi.org/10.21203/rs.3.rs-148870/v1

License: (c) (i) This work is licensed under a Creative Commons Attribution 4.0 International License. Read Full License 


\title{
Institutional Quality Causes Social Trust: Experimental Evidence on Trusting Under the Shadow of Doubt
}

\author{
Andrea F.M. Martinangeli ${ }^{1}$, Marina Povitkina ${ }^{2,3}$, Sverker C. Jagers ${ }^{3}$, and Bo \\ Rothstein $^{3}$ \\ ${ }^{1}$ Max Planck Institute for Tax Law and Public Finance \\ ${ }^{2}$ University of Oslo \\ ${ }^{3}$ University of Gothenburg
}

\begin{abstract}
Social trust underlies virtually any social and economic interaction and is a crucial ingredient for successful collective action. What causes social trust to develop, however, remains poorly understood. Institutional quality has been proposed as a candidate driver and has been shown to correlate with social trust. We provide experimental evidence for the causal direction of this relationship. We first exogenously expose the participants to institutions of different quality, defined as their ability to prevent corrupt behaviours on behalf of administrators. We then measure social trust among the participants using a trust game. We find that individuals exposed to settings with low institutional quality trust others significantly less. Moreover, using novel survey data we show that our experimental results correspond to correlational patterns usually found across countries. The paper makes a step forward in the decades-long search for the causality between institutional quality and social trust.
\end{abstract}

Martinangeli and Povitkina contributed equally to this project and their names are ordered alphabetically.

JEL classification Codes: D63, D73

Keywords: Social trust, quality of government, corruption, embezzlement

Conflicting Interests: None

Ethics Clearance: Ethics Council of the Max Planck Society, Decision nr. 2020-04 
Acknowledgments: The authors are grateful to Natalia Alvarado Pachon for technical assistance, and to Tobias Bach, Alexander Cappelen, Fredrik Carlsson, Etienne Dagorn, Carl Dahlström, Gianmarco Daniele, Claes Ek, Katinka Holtsmark, Jon Hovi, Steffen Kallbekken, Carl Henrik Knutsen, Staffan Kumlin, Elina Lampi, Åsa Löfgren, Øivind Schøyen, Aksel Sundström, Sofia Vera, Tore Wig, Lisa Windsteiger, researchers at the Quality of Government Institute, Center for Collective Action Research, Max Planck Institute for Tax Law and Public Finance, FAIR-NHH Bergen, and at CREM Université de Rennes 1 for valuable comments and feedback. Financial support was provided by the Swedish Research Council, grant number 2019-02680. 
Social trust underlies virtually any social interaction, laying the premises for social and economic prosperity (Arrow, 1972; Dearmon and Grier, 2009; Algan and Cahuc, 2010). As such, it is a necessary component for the successful solution of social dilemmas such as pollution abatement, tax compliance, the maintenance of sound and constructive political and economic relationships, and containment of epidemics, to name a few (Ostrom, 2005; Daniele and Geys, 2015; Daniele et al., 2020). In modern day impersonal relationships and transactions, moreover, it stretches beyond individuals who know each other or interact face-to-face. Identifying the determinants of social trust has therefore been and remains today one of the key problems in economics, political science, and social psychology as it might provide social planners and policy makers with viable instruments to achieve the desirable social outcomes. An intensely debated and yet unresolved problem is, in this respect, the role of institutional quality in determining social trust. ${ }^{1}$ This study relies on a novel experimental paradigm to make one step further in clarifying this conundrum and documents the existence of a causal effect of institutional quality on social trust.

High levels of social trust are generally attributes of societies characterised by high institutional quality. In the Nordic countries, known for their low levels of corruption, more than $60 \%$ of the population consistently reports that most people can be trusted. The percentage drops to less than $10 \%$ in countries suffering from widespread corruption (Ortiz-Ospina and Roser, 2020). The evidence for a positive correlation between institutional quality and social trust is strong and robust (Rothstein and Uslaner, 2005; Kumlin and Rothstein, 2005; Bjørnskov, 2007; Freitag and Bühlmann, 2009; Charron and Rothstein, 2016; Knack and Zak, 2003; Knack and Keefer, 1997; Delhey and Newton, 2005). Despite the intense and decades-long debate, however, the causal link tying the two is neither straightforward, nor unequivocally established due to the numerous confounders (e.g. cross-country differences in underlying historical, social, and political conditions, culture, economic development, among others) and to the slow-moving nature of both social trust and institutional quality. Moreover, while many scholars hold the view that stronger institutions are the pre-conditions for social trust to develop (e.g., Rothstein, 2000; Rothstein and Stolle, 2008; Rothstein and Eek, 2009; Dinesen and Hooghe, 2010; Dinesen, 2012a; Rothstein, 2013; Sønderskov and Dinesen, 2014; Spadaro et al., 2020), others claim that more trusting societies are better equipped to establish institutions of better quality (e.g., Lambsdorff, 2002; Uslaner, 2002; Bjørnskov, 2010; Graeff and Svendsen, 2013; Wroe et al.,

\footnotetext{
${ }^{1}$ Institutions are here intended as the formal and informal "rules" that shape human interactions (North, 1990, p. 3).
} 
2013).

Despite there are a few studies that resort to experimental methods with the aim to break these endogeneities, the causal relationship remains elusive due to their cross-cultural nature. Rothstein and Eek find that students in Sweden and Romania who experienced corruption abroad display lower social trust (Rothstein and Eek, 2009). Dinesen and his colleagues find that social trust in immigrants from low trust/high corruption countries increases with the number of years spent in high trust/low corruption Denmark (Dinesen, 2012a,b; Dinesen and Hooghe, 2010; Nannestad et al., 2014; Sønderskov and Dinesen, 2014). As You notes in his comprehensive review of the literature, more empirical investigations are needed to understand whether institutional quality indeed impacts social trust (You, 2018, p. 11). ${ }^{2}$

In this paper we take up this challenge and investigate whether impartial and trustworthy institutions can be regarded as determinants of social trust (Tarrow, 1996; Levi, 1998; Rothstein, 2000, 2011). Numerous scholars argue that legal systems, ensuring reliable contracts, securing rights, sanctioning non-compliance, protecting minorities, and supporting participation provide citizens with the necessary assurance that others will adhere to the prescribed codes of behavior (Levi, 1998; Rothstein and Stolle, 2008; Spadaro et al., 2020). Fair, impartial, and trustworthy institutions foster moreover a sense of group membership and commonality among citizens, aligning social and individual goals, which favors the development of social trust (De Cremer et al., 2005; Ostrom, 2005; Wenzel, 2007; Wichardt, 2008; Martinangeli and Martinsson, 2020). We thus hypothesize that institutions of higher quality, further operationalised as institutions that are capable of preventing corrupt behaviours, have a positive causal effect on social trust. ${ }^{3}$

In order to provide evidence for a causal relationship running from institutional quality to social trust, we adopt an experimental paradigm consisting of two phases. In the first phase, we expose the participants to exogenously varied levels of institutional quality by letting them play a modified public good game. This game allows us to introduce an institution and experimentally vary its quality, mimicking the context in which the consequences of institutional quality on individual and collective welfare take place in the real

\footnotetext{
${ }^{2}$ Scholars have argued that trust may also be found among those involved in corruption and those who profit from an unregulated social environment, such that widespread corruption is associated with higher levels of social trust. Trust that is functional in corrupt networks, however, is considered to be particularised rather than generalized/social trust (Uslaner, 2002) and is beyond the scope of this paper.

${ }^{3}$ We do not investigate whether causation also runs in the opposite direction, leaving this question open for future research.
} 
world. The standard version stylises in fact the raising of funds for public goods (e.g. public schools, roads, and green spaces). In the game, participants in groups of 3 all choose how much to contribute to a common good out of a personal endowment and how much to keep for themselves. Each group member then receives in return a fraction of the total amount contributed by the whole group. This way, society (the group) benefits most if everyone contributes the maximum possible amount to the common good, although in each individual's self-interest is to keep his or her own endowment, let others contribute, and acquire the benefits of others' contributions. ${ }^{4}$

Our variant of the game introduces an agent acting as an administrator of public money and an institutional framework which we experimentally manipulate by varying its ability to prevent corrupt behaviour on behalf of the administrator. The public administrator is part of the group, and is mandated to collect each of the group members' contributions to the public good, including their own, and to redistribute them according to the standard public good rule - a task, which is normally automated in experimental implementations of the game. Crucially, the administrator has the opportunity to embezzle any fraction of the collected amount. ${ }^{5}$ We experimentally vary the probability with which embezzlement attempts by the administrator will be detected and prevented by the institutions: Perfect institutions allow for a $0 \%$ chance of embezzlement success, slightly imperfect institutions allow embezzlement attempts to succeed with a $1 \%$ probability, and imperfect institutions allow embezzlement attempts to succeed with $50 \%$ chance. We are interested in the impact of institutional quality, i.e. the ability of the institutions to prevent eventual corrupt behaviour, and not in the fact of embezzlement per se. We therefore inform the participants about the probabilities with which embezzlement attempts will be detected, but do not provide feedback on individual contributions, on the presence, size, and success of embezzlement attempts, or whether checks on the administrator's behaviours occurred. Instead we elicit incentivised beliefs about others' contributions and about the administrators' embezzlement behaviour.

In the second phase, we measure social trust among subjects who have experienced institutions of different quality using a trust game (Berg et al., 1995). After the public good phase we break up the groups and re-match the group members, who did not act as administrators, in stranger pairs. A sender and a receiver are each endowed with 6

\footnotetext{
${ }^{4}$ See supplementary material 1 for more details about the standard public good game and our variant.

${ }^{5}$ We do not explicitly allow nor sanction embezzlement. However, our treatments affect the behavior of the administrators as expected, see footnote 8
} 
euros. The sender can choose to send any integer amount to the receiver, who will receive the amount doubled. The receiver can then return any integer amount of what is in her possession to the receiver. There is an element of trust in this transaction: In order to send any amount, the sender must trust the receiver to send back at least as much as she sent.

With this set-up, we are able to directly observe, under hard test conditions but in a simple and parsimonious experimental design, the impact of institutional quality on generalised social trust: ${ }^{6}$ Reciprocity between the administrators and the group members, as well as among group members themselves, are excluded. Our analysis allows us to remove expectations about other group members' cooperativeness, about the administrator's embezzlement attempts, and earning effects, as confounders of institutional quality in driving social trust.

\section{Results}

\section{Experimental results}

Table 1 displays the results from a regression of the amounts sent by group members (non administrators) in the trust phase of the experiment on the experimental conditions. All regressions control for the order in which the subject participated in the trust game, the subject's gender, age, and profession. ${ }^{7}$ We control for the beliefs about the amount the administrator sends for redistribution normalised against total group contributions (Belief(e)), for beliefs about the other group member's contribution (Belief(c)), for own contribution, and for total group contributions. Corresponding Tobit regressions reported in supplementary material 2 confirm the results in Table 1.

The results show that trusting behaviour is highly sensitive to the experimental condition. Even a small $1 \%$ chance that an embezzlement attempt might succeed significantly reduces the amounts sent by almost 80 cents. When moving to a $50 \%$ probability of successful embezzlement attempts, the amount sent decreases on average by almost 1.2 Euros.

\footnotetext{
${ }^{6}$ We acknowledge that institutional quality includes many dimensions, with corruption (or more specifically embezzlement as an aspect of corruption) being only one of them. We nevertheless believe that reducing institutional quality to one dimension - as its ability to prevent, in our operationalisation, embezzlement - is crucial for obtaining clear-cut testable predictions and a clean experimental design. We leave further tests of other aspects of institutional quality on social trust for future research.

${ }^{7} \mathrm{~A}$ Kruskall-Wallis test cannot reject the null of equality in the amounts sent between subjects who participated as senders first and receivers later or vice versa; $\mathrm{p}$-value $=0.622$.
} 


\begin{tabular}{|c|c|c|c|c|c|}
\hline & Model 1 & Model 2 & Model 3 & Model 4 & Model 5 \\
\hline & \multicolumn{5}{|c|}{ Trust game: amount sent by the group members } \\
\hline \multicolumn{6}{|l|}{ Condition Zero } \\
\hline \multirow[t]{2}{*}{$\overline{\text { Condition One }}$} & -0.697 & $-0.724^{*}$ & $-0.778^{*}$ & $-0.766^{*}$ & $-0.794^{*}$ \\
\hline & $(0.435)$ & $(0.413)$ & $(0.412)$ & $(0.413)$ & $(0.405)$ \\
\hline \multirow[t]{2}{*}{ Condition Fifty } & $-1.274^{* * *}$ & $-1.177^{* * *}$ & $-1.198 * * *$ & $-1.159^{* * *}$ & $-1.029 * *$ \\
\hline & $(0.433)$ & $(0.433)$ & $(0.430)$ & $(0.432)$ & $(0.442)$ \\
\hline \multirow[t]{2}{*}{ Own contribution } & & $0.117^{* * *}$ & $0.086^{* * *}$ & $0.095^{* *}$ & $0.090 * *$ \\
\hline & & $(0.027)$ & $(0.033)$ & $(0.037)$ & $(0.037)$ \\
\hline \multirow[t]{2}{*}{ Group contributions } & & & $0.039^{*}$ & 0.026 & 0.029 \\
\hline & & & $(0.023)$ & $(0.032)$ & $(0.031)$ \\
\hline \multirow[t]{2}{*}{ Belief(c) } & & & & 0.034 & 0.034 \\
\hline & & & & $(0.049)$ & $(0.048)$ \\
\hline \multirow[t]{2}{*}{ Belief(e) } & & & & & $1.247^{*}$ \\
\hline & & & & & $(0.657)$ \\
\hline \multirow[t]{2}{*}{ Sender first } & -0.181 & -0.245 & -0.279 & -0.255 & -0.203 \\
\hline & $(0.356)$ & $(0.342)$ & $(0.342)$ & $(0.342)$ & $(0.337)$ \\
\hline \multirow[t]{2}{*}{ Constant } & $3.596^{* * *}$ & $3.241^{* * *}$ & $2.660^{* * *}$ & $2.599 * * *$ & $1.718^{* *}$ \\
\hline & $(0.657)$ & $(0.613)$ & $(0.742)$ & $(0.734)$ & $(0.814)$ \\
\hline Individual controls & $\checkmark$ & $\checkmark$ & $\checkmark$ & $\checkmark$ & $\checkmark$ \\
\hline Observations & 174 & 174 & 174 & 174 & 174 \\
\hline R-squared & 0.071 & 0.151 & 0.166 & 0.169 & 0.187 \\
\hline
\end{tabular}

Table 1: OLS regression of amounts sent in the trust phase. The analysis excludes the administrators. We control for the order in which the subject participated in the trust game as sender and receiver (Sender first), age, gender, and profession. The variable Belief(e) measures normalised beliefs about the amount redistributed by the administrator normalised against the group's total contributions, while Belief(c) measures beliefs about the other group members' contributions.

The effect size is approximately 30\% larger than the one observed for Condition One, though not significantly different. Therefore, amounts sent in the trust game drop significantly when embezzlement attempts in the public good phase have even a small chance of succeeding.

These results support the hypothesis that an exposure to the institutions incapable of perfectly harnessing corrupt behaviour on behalf of public officials erodes trust among strangers. One might ask whether the decrease in willingness to trust others following exposure to imperfect institutions is driven by differences in expected earnings from the public good phase across conditions. We introduced several precautions to avoid this confounder. First, the wording we used in designing our conditions excludes the possibility 
that there are differences in the participants' focus on unethical behaviour across conditions. Second, earning expectations can be driven either by expected total group contributions and/or expected embezzlement. We explicitly revealed total group contributions when eliciting our subjects' beliefs about embezzlement (recall that the subjects were unaware of whether embezzlement attempts occurred or succeeded). This choice allows us to control for, and fix beliefs about, total group contributions in our regressions in Table 3, and to provide a meaningful benchmark to standardise beliefs about embezzlement. Table 2 reports average total group contributions.

\begin{tabular}{lccc}
\hline Condition & $\begin{array}{c}\text { Total group } \\
\text { contributions }\end{array}$ & Standard Deviation & $\mathrm{KW}$ p-value \\
Zero & 19.25 & 8.16 & \\
One & 21.45 & 10.71 & 0.556 \\
Fifty & 19.58 & 9.15 & \\
\multicolumn{4}{c}{ Administrators excluded } \\
\hline Condition & Group member & Standard Deviation & KW p-value \\
& contributions & & \\
\hline \multirow{4}{*}{ Zero } & 12.97 & 7.54 & 0.644 \\
One & 14.09 & 9.57 & \\
Fifty & 11.67 & 8.34 & \\
\hline
\end{tabular}

Table 2: Total contributions collected on average in each condition. The last column displays the p-value from a two-sided Kruskal-Wallis (KW) test of equality across the three conditions.

Two-sided Kruskal-Wallis tests do not allow us to reject the null hypothesis that total group contributions are equal across conditions (see also the regressions in supplementary material 3): Group cooperativeness therefore cannot explain the variation in trusting behaviours (as also evident from Table 3). Beliefs about embezzlement do not explain our experimental effects either. The models in Table 3 control for beliefs about embezzlement and about other group members' contributions. The impact of institutional quality remains stable, strong, and significant beyond any efficiency or expected earnings concern. ${ }^{8}$ Notice that we do not find any significant effect of our conditions on trustworthiness (proportions sent back), with a Kruskal-Wallis test rejecting the null of equality across conditions

\footnotetext{
${ }^{8}$ Beliefs might be endogenous to the experimental conditions. As the analyses in supplementary material 4 demonstrate, beliefs about embezzlement decrease with institutional quality. Beliefs about others' contributions do not vary with the experimental conditions.
} 
$(\mathrm{KW}$ p-value $=0.774)$. This finding confirms that earning expectations do not explain our results. $^{9}$

In what follows, by using publicly available survey data, we show that a negative association between administrative embezzlement and social trust can also be observed across countries. This result substantiates and offers insights into real world regularities against which to interpret our experimental findings.

\section{Supporting survey evidence}

In our correlational analysis, we compare the levels of institutional quality and social trust across countries. We measure the level of social trust using a weighted country-averaged response to the question "Generally speaking, would you say that most people can be trusted or that you need to be very careful in dealing with people?" from the World Value Survey (Inglehart et al., 2014) and European Value Survey (EVS, 2011), merged version available in the Quality of Government dataset (Teorell et al., 2020).

To remain consistent with our experimental investigation, we here operationalise institutional quality as the prevalence of embezzlement in each country, and report analyses using broader definitions of institutional quality in supplementary material 5 . We use embezzlement indicators recently collected by the Varieties of Democracy (V-Dem) Institute (Coppedge et al., 2020a) consisting of expert answers to the questions: "How often do public sector employees steal, embezzle, or misappropriate public funds or other state resources for personal or family use?" and "How often do members of the executive (the head of state, the head of government, and cabinet ministers), or their agents, steal, embezzle, or misappropriate public funds or other state resources for personal or family use?" (Coppedge et al., 2020b; Pemstein et al., 2020). We reverse the indicators, so that higher values mean larger extent of embezzlement. We perform an OLS regression analysis using cross-sectional data from the latest year when the measure of trust is available.

We control for the natural logarithm of gross domestic product (GDP) per capita from

\footnotetext{
${ }^{9}$ Our experimental conditions however affected the embezzlement behavior of administrators as expected, implying that our treatments "worked". Higher quality institutions, being more effective at preventing the success of embezzlement attempts, prompted fewer attempts. In Condition Zero, there were no embezzlement attempts, though attempts were in principle possible. In Condition One, 4 out of 31 administrators attempted to embezzle, with $12 \%$ of the group's resources on average embezzled in this condition, regardless of embezzlement success. In Condition Fifty, 11 out of 24 administrators made embezzlement attempts, such that the average embezzlement rate regardless of embezzlement success is $30 \%$ in this condition. Kruskal-Wallis tests reject the null hypothesis of equality of embezzlement behaviours across conditions (KW p-value=0.015).
} 


\begin{tabular}{|c|c|c|c|c|}
\hline & Model 1 & $\begin{array}{r}\text { Model } 2 \\
\text { Socia }\end{array}$ & $\begin{array}{l}\text { Model } 3 \\
\text { trust }\end{array}$ & Model 4 \\
\hline Adm. embez. & $\begin{array}{c}-0.045^{* * *} \\
(0.015)\end{array}$ & $\begin{array}{c}-0.091^{* * *} \\
(0.024)\end{array}$ & & \\
\hline Exec. embez. & & & $\begin{array}{c}-0.033^{*} \\
(0.019)\end{array}$ & $\begin{array}{c}-0.095^{* *} \\
(0.039)\end{array}$ \\
\hline Ln GDP p.c. & $\begin{array}{c}0.033^{* * *} \\
(0.013)\end{array}$ & $\begin{array}{c}0.032 \\
(0.028)\end{array}$ & $\begin{array}{c}0.048^{* * *} \\
(0.012)\end{array}$ & $\begin{array}{c}0.054^{* *} \\
(0.027)\end{array}$ \\
\hline Ln ethn. gr. & $\begin{array}{c}0.012 \\
(0.024)\end{array}$ & $\begin{array}{c}0.024 \\
(0.033)\end{array}$ & $\begin{array}{c}0.007 \\
(0.024)\end{array}$ & $\begin{array}{l}-0.008 \\
(0.032)\end{array}$ \\
\hline Homicide rate & $\begin{array}{c}-0.003^{* * *} \\
(0.001)\end{array}$ & $\begin{array}{c}0.002 \\
(0.002)\end{array}$ & $\begin{array}{c}-0.004^{* * *} \\
(0.001)\end{array}$ & $\begin{array}{c}0.001 \\
(0.003)\end{array}$ \\
\hline Elect. dem. & $\begin{array}{c}-0.155^{*} \\
(0.085)\end{array}$ & $\begin{array}{c}-0.521^{* * *} \\
(0.181)\end{array}$ & $\begin{array}{l}-0.117 \\
(0.091)\end{array}$ & $\begin{array}{c}-0.560^{* * *} \\
(0.196)\end{array}$ \\
\hline GINI (WB est.) & & $\begin{array}{c}-0.012^{* * *} \\
(0.003)\end{array}$ & & $\begin{array}{c}-0.011^{* * *} \\
(0.003)\end{array}$ \\
\hline Constant & $\begin{array}{c}0.252 \\
(0.158)\end{array}$ & $\begin{array}{c}1.087^{* * *} \\
(0.347)\end{array}$ & $\begin{array}{c}0.003 \\
(0.124)\end{array}$ & $\begin{array}{c}0.779 * * \\
(0.367)\end{array}$ \\
\hline Observations & 97 & 57 & 97 & 57 \\
\hline R-squared & 0.340 & 0.522 & 0.305 & 0.477 \\
\hline
\end{tabular}

Table 3: OLS regression of average social trust on administrative and executive embezzlement across countries. The regressions control for ln GDP per capita, ln number of politically active ethnic groups, the homicide rate, the score on the electoral democracy index, and the GINI index (World Bank estimate).

the World Development Indicators (2016), as it is believed to correlate with social trust (Knack and Keefer, 1997), the level of inequality measured by GINI index (World Bank, 2016), as inequalities impede trust (Barone and Mocetti, 2016), and homicide rates (World Health Organization, 2019), as people living in areas characterized by high levels of crime rates tend to trust each other less (Rosenfeld et al., 2001). All measures are available in the Quality of Government dataset (Teorell et al., 2020). Further, we control for ethnic fragmentation (Ln ethn. gr.), measured by the number of politically relevant groups in a country (Vogt et al., 2015), as divided societies tend to be less trusting (Bjørnskov, 2008), and the level of democracy measured by the Electoral Democracy Index (Elect. dem.) from the V-Dem dataset (Coppedge et al., 2020a), as democracy has been found to affect social trust (Ljunge, 2014).

Table 3 presents the results. Models 1 and 2 show the relationship between the average levels of social trust per country and the level of embezzlement in the public sector. 
The relationship is negative and significant, implying that countries with higher extent of embezzlement practices in the public sector on average tend to have lower levels of social trust. Moving one step (out of 8) on the index of public sector embezzlement corresponds to a lower level of trust by 0.05 (out of the 0-1 interval) in the sample of 97 countries and 0.09 in the sample of 57 countries. The reported coefficients mean that one standard deviation increase in embezzlement translates into a $41.9 \%$ and $84.7 \%$ of a standard deviation decrease in social trust respectively. Models 3 and 4 present the results for the same analysis with the executive embezzlement levels used as an independent variable instead. The relationship between executive embezzlement and the average levels of social trust is also negative and significant. Having a one-unit higher level of executive embezzlement (out of 5 ) corresponds to a lower level of trust by 0.03 (out of the $0-1$ interval) in the model with 97 countries and 0.095 in the model with 57 countries. These coefficients correspond to $21.5 \%$ and $62.2 \%$ of a standard deviation in Models 3 and 4 respectively. Social trust is therefore negatively associated with the level of administrative and executive embezzlement across countries.

Supplementary material 5 presents further evidence for a positive and strong association between institutional quality, more broadly, and social trust across European regions, based on the unique and recently collected data from the European Quality of Government Survey (Charron et al., 2019).

\section{Discussion}

This article expands our understanding of the relationship between social trust and institutions that shape human interactions in a society. We address a so far unresolved question in the empirical social-scientific research: Does institutional quality influence social trust? Despite decades of accumulated evidence of a strong and positive correlation between the two, the existence of a causal link has not yet been established. We adopted a simple experimental paradigm allowing us to exogenously manipulate the subjects' exposure to institutions of different quality before eliciting their levels of trust. To our knowledge, this article is the first to report the impact of exposure to different levels of institutional quality on social trust in a setting eliminating the social, economic, political, and historical confounders that plague cross-cultural research with survey data.

The results from our experiment lend credibility to the claim that high quality institutions are among the pre-conditions for a trusting society. These findings are consequential: 
A trusting social fabric is better equipped to develop the full potential of socio-economic interactions (Arrow, 1972), and to provide public goods and coordinated collective action that benefit society as a whole. For instance, managing common pool resources, paying into social welfare systems, or containing the adverse consequences of natural disasters, such as pandemics, all require individuals to trust that others will not free ride (Ostrom, 2005; Daniele and Geys, 2015; Daniele et al., 2020). Social trust can moreover be a viable substitute to costly monitoring in the presence of incomplete or hardly enforceable contracts (Fukuyama, 1995; La Porta et al., 1997).

Crucially, an institutional framework, as opposed to social trust itself, can be manipulated and its quality can be, at least to some extent, improved by design. Our results suggest that social planners aiming at fostering social trust can, by virtue of the causal relationship uncovered here, count on institutional design among the tools at their disposal. Setting up institutions that provide individuals with the necessary assurance that antisocial and socially harmful behaviour will be effectively harnessed might be an open avenue towards achieving a more trusting social fabric.

Our findings also open numerous avenues for how to further our understanding of the institutions-social trust nexus. First, while we find evidence for a causal effect of institutional quality on social trust, our design does not unpack, neither confirming nor disconfirming, the existence of a causal link running in the opposite direction: From social trust to better institutions (e.g., Uslaner, 2002; Bjørnskov, 2010). It might well be that institutional quality and social trust are locked in a virtuous (or vicious) circle. The resolution of this question is beyond the scope of this paper and we leave it for future research. Further, a natural step ahead is to investigate whether the causal effects reported here are mediated by a drop in the expected trustworthiness of others. Answering such question is especially important as there is a lack of an effect on observed trustworthiness in our experiment: Unwarranted mistrust might prove a threat to social cohesion and lead to wasteful protective practices.

Another relevant question is where the beliefs that administrators engage in less corrupt behaviours in the presence of stronger institutions stems from. One possibility is they originate from the fact that such behaviours are rendered (nearly) pointless by the institutions themselves. A second possibility is that they originate from a perception of the administrators as being more ethical per se. The latter perspective envisages that institutions create a common understanding of which practices are considered acceptable by most and to which most are expected to adhere. 


\section{Methods}

This section describes our experimental design. We run 11 sessions at the ECONLAB laboratory of the Max Planck Institute of Tax Law and Public Finance in Munich, Germany, with 264 subjects at the end of February 2020. An informed consent statement was collected from each participant upon admittance to the sessions. The English transcription of the experimental instructions can be found in the supplementary material. ${ }^{10}$ The average payout was 22 Euros and completion time was approximately 45 minutes.

\section{Public good phase}

As illustrated earlier, we introduce an administrator of group contributions and an institutional framework more or less capable of preventing corrupt behaviours on their behalf. The public good game was played only once to eliminate any reputation incentive for the administrator. We provided no feedback on the individual contributions or on the administrator's choice of how much to redistribute. We collected the group members' incentivised beliefs about each other's contributions and about the amount of total contributions which would be redistributed by the administrator (i.e. the group members' beliefs about the administrator's embezzlement behaviour). The incentivisation was the following: a non-administrator group member guessing the other non-administrator group member's contribution within a 1 Euro margin of the true amount contributed would earn 1 extra Euro. For deviations larger than 1 Euro, they would earn 1 euro divided by the size of the deviation. We used a similar incentivisation for beliefs about the amount that the administrator sends for redistribution, only that the tolerance margin around the true value in this case was 5 Euros.

Experimental conditions We introduce exogenous variation in institutional quality by varying the probability with which embezzlement is detected and prevented. The software randomly drew a number $d \sim U(0,99)$ where $\mathrm{U}$ denotes a uniform distribution of integers. A check on the amount entered by the administrator would be performed if $d \geq t$ where $t \in\{0,1,50\}$ according to the experimental condition (varied between sessions). If a check occurred and the amount entered for redistribution was incorrect, an error message asked the administrator to revise the entry for the game to continue. The group members were

\footnotetext{
${ }^{10}$ The minimal detectable effect over standardised social trust measures (administrators excluded) is $M D E=0.47$ at $\alpha=0.05$ and power $p=0.8$.
} 
not made aware of whether any embezzlement attempt occurred, its size, its success, nor whether a check on behalf of the institutions on the amount redistributed had occurred. We aimed at eliminating the risk that our internvention might differently focalise the subjects' attention on antisociality and unethical behaviour across conditions, or might induce demand effects (Zizzo, 2010). To this end, first, the same wording was used in all our conditions. Second, we kept our wording neutral, only informing the subjects that the administrators' entry would be checked with a given probability.

Condition Zero In condition Zero (96 subjects), we modelled institutions fully capable of preventing corrupt behavior on behalf of public officials: A $0 \%$ chance that any attempt of stealing the group's contributions might succeed. Here, any attempt at embezzlement on behalf of the administrator was met with an error message (See the instructions in supplementary material 7).

Condition One In condition One (96 subjects), the institutions allow for a small chance, $1 \%$, that an embezzlement attempt might succeed. The instructions communicated to the subjects that the amount entered for redistribution by the administrator would be checked with $99 \%$ probability.

Condition Fifty In condition Fifty (72 subjects), the institutions allowed for a 50\% chance that an embezzlement attempt might succeed. The instructions communicated to the subjects that the amount entered for redistribution by the administrator would be checked with $50 \%$ probability.

\section{Trust phase}

In the second phase, we elicited a behavioural measure of social trust among the subjects using a standard trust game (Berg et al., 1995). We matched the subjects in pairs consisting of a sender and a receiver, and each received an endowment of six euros. The senders chose to send any integer amount of their endowment to the receivers and keep the rest. The receivers would receive the amount doubled, and could then choose to send any integer amount of their endowment plus what they had received back to the senders. As receivers maximise their payoff by sending back nothing, it is a dominant strategy for the senders to keep everything for themselves. 
As we are interested in the impact of the institutional quality on people's willingness to trust others, we are particularly interested in the trusting behaviour of the group members (not administrators). For this reason, group members only played the trust game with other group members (not administrators), and were made aware of this. Moreover we made the subjects aware that the public good phase groups were broken up after the end of that phase, and that for the trust game they would be randomly re-matched with other group members from the session. We can thus rule out any impact of reciprocal behaviours across phases on the choices in the trust game. By breaking up the public good group and organising subjects in new pairs, we decouple what actually happened in the public good phase from the trust game and are able to isolate the impact of exposure to a weaker institutions on generalised social trust. All subjects played both the roles of sender and receiver in random order and with different partners. Moreover, we kept feedback at the minimum, only communicating to the receivers the amount available to be transferred back to the sender. Additionally, the instructions informed the players that only one of the two rounds, randomly selected, was valid for payment.

After the trust game was completed, the subjects answered a number of socio-demographic questions. Finally, we debriefed the subjects about their payoffs, including which of the two phases would be paid out.

\section{References}

Algan, Y. and Cahuc, P. (2010). Inherited Trust and Growth. American Economic Review, 100(5):2060-2092.

Arrow, K. (1972). Gifts and Exchanges. Philosophy and Public Affairs, I:343-362.

Barone, G. and Mocetti, S. (2016). Inequality and trust: new evidence from panel data. Economic Inquiry, 54(2):794-809.

Berg, J., Dickhaut, J., and McCabe, K. (1995). Trust, Reciprocity, and Social History. Games and Economic Behavior, 10(1):122-142.

Bjørnskov, C. (2007). Economic growth: a social capital survey. In Svendsen, G. and Svendsen, G., editors, Handbook of Social Capital. Edward Elgar, Cheltenham.

Bjørnskov, C. (2008). Social trust and fractionalization: A possible reinterpretation. European Sociological Review, 24(3):271-283. 
Bjørnskov, C. (2010). How does social trust lead to better governance? an attempt to separate electoral and bureaucratic mechanisms. Public Choice, 144(1-2):323-346.

Charron, N., Lapuente, V., and Annoni, P. (2019). Measuring quality of government in eu regions across space and time. Papers in Regional Science, 98(5):1925-1953.

Charron, N. and Rothstein, B. (2016). Does education lead to higher generalized trust? the importance of quality of government. International journal of educational development, 50:59-73.

Coppedge, M., Gerring, J., Knutsen, C. H., Lindberg, S. I., Teorell, J., Altman, D., Bernhard, M., Fish, M. S., Glynn, A., Hicken, A., Lührmann, A., Marquardt, K. L., McMann, K., Paxton, P., Pemstein, D., Seim, B., Sigman, R., Skaaning, S.-E., Staton, J., Wilson, S., Cornell, A., Alizada, N., Gastaldi, L., Gjerløw, H., Hindle, G., Ilchenko, N., Maxwell, L., Mechkova, V., Medzihorsky, J., von Römer, J., Sundström, A., Tzelgov, E., Wang, Y.-t., Wig, T., and Ziblatt, D. (2020a). V-Dem [Country-Year/Country-Date] Dataset v10". Varieties of Democracy (V-Dem) Project.

Coppedge, M., Gerring, J., Knutsen, C. H., Lindberg, S. I., Teorell, J., Altman, D., Bernhard, M., Fish, M. S., Glynn, A., Hicken, A., Lührmann, A., Marquardt, K. L., McMann, K., Paxton, P., Pemstein, D., Seim, B., Sigman, R., Skaaning, S.-E., Staton, J., Cornell, A., Gastaldi, L., Gjerløw, H., Mechkova, V., von Römer, J., Sundtröm, A., Tzelgov, E., Uberti, L., Wang, Y.-t., Wig, T., and Ziblatt, D. (2020b). V-Dem Codebook v10. University of Gothenburg, Varieties of Democracy (V-Dem) Project.

Daniele, G. and Geys, B. (2015). Interpersonal trust and welfare state support. European Journal of Political Economy, 39:1-12.

Daniele, G., Martinangeli, A. F. M., Passarelli, F., Sas, W., and Windsteiger, L. (2020). Wind of Change? Experimental Survey Evidence on the Covid-19 Shock and SocioPolitical Attitudes in Europe. SSRN Scholarly Paper ID 3671674, Social Science Research Network, Rochester, NY.

De Cremer, D., Tyler, T. R., and den Ouden, N. (2005). Managing cooperation via procedural fairness: The mediating influence of self-other merging. Journal of Economic Psychology, 26(3):393-406. 
Dearmon, J. and Grier, K. (2009). Trust and development. Journal of Economic Behavior E Organization, 71(2):210-220.

Delhey, J. and Newton, K. (2005). Predicting cross-national levels of social trust: global pattern or nordic exceptionalism? European sociological review, 21(4):311-327.

Dinesen, P. T. (2012a). Does generalized (dis) trust travel? examining the impact of cultural heritage and destination-country environment on trust of immigrants. Political Psychology, 33(4):495-511.

Dinesen, P. T. (2012b). Parental transmission of trust or perceptions of institutional fairness: generalized trust of non-western immigrants in a high-trust society. Comparative Politics, 44(3):273-289.

Dinesen, P. T. and Hooghe, M. (2010). When in rome, do as the romans do: the acculturation of generalized trust among immigrants in western europe. International Migration Review, 44(3):697-727.

EVS (2011). European Values Study 1981-2008, Longitudinal Data File. ZA4804 Data File Version 2.0.0. GESIS Data Archive, Cologne.

Freitag, M. and Bühlmann, M. (2009). Crafting trust: The role of political institutions in a comparative perspective. Comparative Political Studies, 42(12):1537-1566.

Fukuyama, F. (1995). Trust: The social virtues and the creation of prosperity, volume 99. Free press New York.

Graeff, P. and Svendsen, G. T. (2013). Trust and corruption: The influence of positive and negative social capital on the economic development in the european union. Quality $\&$ Quantity, 47(5):2829-2846.

Inglehart, R., Haerpfer, C., Moreno, A., Welzel, C., Kizilova, K., Diez-Medrano, J., Lagos, M., Norris, P., Ponarin, E., Puranen, B., and et al. (2014). World Values Survey: All Rounds - Country-Pooled Datafile 1981-2014. JD Systems Institute, Madrid.

Knack, S. and Keefer, P. (1997). Does social capital have an economic payoff? a crosscountry investigation. The Quarterly journal of economics, 112(4):1251-1288. 
Knack, S. and Zak, P. J. (2003). Building trust: public policy, interpersonal trust, and economic development. Supreme court economic review, 10:91-107.

Kumlin, S. and Rothstein, B. (2005). Making and breaking social capital: The impact of welfare-state institutions. Comparative Political Studies, 38(4):339-365.

La Porta, R., Lopez-De-Silanes, F., Shleifer, A., and Vishny, R. (1997). Trust in large organizations. American Economic Review, 88(2):333-338.

Lambsdorff, J. G. (2002). How confidence facilitates illegal transactions: An empirical approach. American Journal of Economics and Sociology, pages 829-853.

Levi, M. (1998). A state of trust. In Braithwaite, V. and Levi, M., editors, Trust and governance. Russell Sage Foundation, New York.

Ljunge, M. (2014). Social capital and political institutions: Evidence that democracy fosters trust. Economics Letters, 122(1):44-49.

Martinangeli, A. F. M. and Martinsson, P. (2020). We, the rich: Inequality, identity and cooperation. Journal of Economic Behavior 83 Organization, 178:249-266.

Nannestad, P., Svendsen, G. T., Dinesen, P. T., and Sønderskov, K. M. (2014). Do institutions or culture determine the level of social trust? the natural experiment of migration from non-western to western countries. Journal of Ethnic and Migration Studies, 40(4):544-565.

North, D. C. (1990). Institutions, institutional change, and economic performance. Cambridge University Press, Cambridge; New York.

Ortiz-Ospina, E. and Roser, M. (2020). Trust. our world in data. URL: https://ourworldindata.org/trust (Date of access: 23.09.2020).

Ostrom, E. (2005). Understanding institutional diversity. Prinston University Press, Prinston, New Jersey.

Pemstein, D., Marquardt, K. L., Tzelgov, E., Wang, Y.-t., Medzihorsky, J., Krusell, J., Miri, F., and von Römer, J. (2020). The V-Dem Measurement Model: La- tent Variable Analysis for Cross-National and Cross-Temporal Expert-Coded Data. 
Rosenfeld, R., Baumer, E. P., and Messner, S. F. (2001). Social capital and homicide. Social Forces, 80(1):283-310.

Rothstein, B. (2000). Trust, social dilemmas and collective memories. Journal of Theoretical Politics, 12(4):477-501.

Rothstein, B. (2011). The quality of government: Corruption, social trust, and inequality in international perspective. University of Chicago Press.

Rothstein, B. (2013). Corruption and social trust: Why the fish rots from the head down. Social Research, 80(4):1009-1032.

Rothstein, B. and Eek, D. (2009). Political corruption and social trust: An experimental approach. Rationality and society, 21(1):81-112.

Rothstein, B. and Stolle, D. (2008). The state and social capital: An institutional theory of generalized trust. Comparative politics, 40(4):441-459.

Rothstein, B. and Uslaner, E. M. (2005). All for all: Equality, corruption, and social trust. World Politics, 58:41.

Sønderskov, K. M. and Dinesen, P. T. (2014). Danish exceptionalism: Explaining the unique increase in social trust over the past 30 years. European Sociological Review, 30(6):782-795.

Spadaro, G., Gangl, K., Van Prooijen, J.-W., Van Lange, P. A., and Mosso, C. O. (2020). Enhancing feelings of security: How institutional trust promotes interpersonal trust. PloS one, 15(9).

Tarrow, S. (1996). Making social science work across space and time: a critical reflection on robert putnam's making democracy work. American political science review, 90(2):389397.

Teorell, J., Dahlberg, S., Holmberg, S., Rothstein, B., Alvarado Pachon, N., and Axelsson, S. (2020). The Quality of Government Standard Dataset, version Jan20. Quality of Government Institute, University of Gothenburg.

Uslaner, E. M. (2002). The moral foundations of trust. Cambridge University Press. 
Vogt, M., Bormann, N.-C., Rüegger, S., Cederman, L.-E., Hunziker, P., and Girardin, L. (2015). Integrating data on ethnicity, geography, and conflict: The ethnic power relations data set family. Journal of Conflict Resolution, 59(7):1327-1342.

Wenzel, M. (2007). The multiplicity of taxpayer identities and their implications for tax ethics. Law \& Policy, 29(1):31-50.

Wichardt, P. C. (2008). Identity and why we cooperate with those we do. Journal of Economic Psychology, 29(2):127-139.

World Bank (2016). World Development Indicators. Available at: https://data. worldbank. org/products/wdi.

World Health Organization (2019). Global health observatory data repository. Available at: http://www. who.int/gho/en/.

Wroe, A., Allen, N., and Birch, S. (2013). The role of political trust in conditioning perceptions of corruption. European Political Science Review, 5(2):175-195.

You, J. (2018). Trust and corruption. In Uslaner, E. M., editor, The Oxford handbook of social and political trust, pages 473-496. Oxford University Press, Oxford.

Zizzo, D. J. (2010). Experimenter demand effects in economic experiments. Experimental Economics, 13(1):75-98. 


\section{Supplementary Files}

This is a list of supplementary files associated with this preprint. Click to download.

- supplementarymaterials.pdf 